\title{
A Novel Anticoagulant Protein with High Affinity to Blood Coagulation Factor Va from Tegillarca granosa
}

\author{
Won-Kyo Jung ${ }^{1,2, \#}$, Hee-Yeon Jo ${ }^{1}$, Zhong-Ji Qian', Young-Ju Jeong ${ }^{3}$, Sae-Gwang Park ${ }^{3}$, \\ Il-Whan $\mathrm{Choi}^{3}$ and Se-Kwon Kim ${ }^{1,2, *}$ \\ ${ }^{1}$ Department of Chemistry, Pukyong National University, Busan 608-737, Republic of Korea \\ ${ }^{2}$ Marine Bioprocess Research Center, Pukyong National University, Busan 608-737, Republic of Korea \\ ${ }^{3}$ Department of Microbiology, College of Medicine and Center for Viral Disease Research, Inje University, \\ Busan 614-735, Republic of Korea
}

Received 12 February 2007, Accepted 9 April 2007

\begin{abstract}
A novel inhibitory protein against blood coagulation factor Va (FVa) was purified from muscle protein of granulated ark (Tegillarca granosa, order Arcoida, marine bivalvia) by consecutive FPLC method using anion exchange and gel permeation chromatography. In the results of ESIQTOF tandem mass analysis and database research, it was revealed that the purified $T$. granosa anticoagulant protein (TGAP) has $7.7 \mathrm{kDa}$ of molecular mass and its partial sequence, HTHLQRAPHPNALGYHGK, has a high identity (64\%) with serine/threonine kinase derived from Rhodopirellula baltica (order Planctomycetales, marine bacteria). TGAP could potently prolong thrombin time (TT), corresponding to inhibition of thrombin (FIIa) formation. Specific factor inhibitory assay showed that TGAP inhibits FVa among the major components of prothrombinase complex. In vitro assay for direct-binding affinity using surface plasmon resonance (SPR) spectrometer indicated that TGAP could be directly bound with FVa. In addition, the binding affinity of FVa to FII was decreased by addition of TGAP in dose-dependant manner $\left(\mathrm{IC}_{50}\right.$ value $=77.9 \mathrm{nM}$ ). These results illustrated that TGAP might interact with a heavy chain of FVa $\left(\mathrm{FVa}_{\mathrm{H}}\right)$ bound to FII in prothrombin complex. The present study elucidated that non-cytotoxic $T$. granosa anticoagulant protein (TGAP) bound to FVa can prolong blood coagulation time by inhibiting conversion of FII to FIIa in blood coagulation cascade. In addition, TGAP did not significantly $(P<0.05)$ show fibrinolytic activity and cytotoxicity on venous endothelial cell line (ECV 304).
\end{abstract}

"Present address: Department of NOAA Sea Grant College Program, Louisiana State University, Baton Rouge, Louisiana 70803

*To whom correspondence should be addressed.

Tel: 82-51-620-6375; Fax: 82-51-620-8147

E-mail: sknkim@pknu.ac.kr
Keywords: Activated factor V (FVa), Anticoagulant protein, Marine bivalvia, Purification, Surface plasmon resonance (SPR), Tegillarca granosa, Thrombin time (TT)

\section{Introduction}

Blood coagulation pathway involves the interaction of many plasma serine proteases known as blood clotting factors. These factors interact with calcium and phospholipid surface to produce a tough fibrin meshwork, which reinforces the friable platelet plug and stops bleeding until tissue repair can occur (Davie et al., 1991). Among these factors, factor V (FV) is a large, single chain, plasma glycoprotein which is an essential component in the blood coagulation cascade. During blood coagulation, the procofactor, $\mathrm{FV}$, is converted to the active cofactor, factor Va (FVa). FVa is a cofactor for the serine protease $\mathrm{FXa}$, and in the presence of calcium ions they collectively assemble on a phospholipid surface to form the prothrombinase complex. The prothrombinase complex is responsible for the rapid conversion of prothrombin (FII) to thrombin (FIIa) (Mann, 1988; Kalafatis et al., 1994).

Blood clotting is processed by various coagulation factors whenever an abnormal vascular condition and exposure to non-endothelial surfaces at sites of vascular injury occurs. As the coagulation factors are interfered by endogenous or exogenous anticoagulants, blood coagulation can be prolonged or stopped. These anticoagulants have been used as convenient tools for exploration of the complex mechanisms of coagulation cascade, and coincidentally, an importance of research for anticoagulants has also arisen with therapeutic purposes like cure of haemophilia (Jung et al., 2002).

During investigation of biomedical and pharmaceutical benefits in marine animals, we recently detected specific FVa- 
inhibitory activity from soluble extracts of granulated ark, Tegillarca granosa. Although it was mainly reported on marine algae-derived carbohydrates and their sulfates as exogenous anthithrombotic materials in the previous studies (Mayer and Hamann, 2004), anticoagulant proteins or peptides have rarely been isolated from marine organisms (Jung et al., 2002; Rajapakse et al., 2005). In this study, we identify biological characterization and molecular interaction of exogenous $T$. granosa anticoagulant protein (TGAP) to FVa in blood coagulation pathway by direct-binding assay using surface plasma resonance (SPR) spectrometer.

\section{Materials and Methods}

Materials. Granulated ark (Tegillarca granosa) was obtained from an aquafarm in Tongyoung, S. Korea. ACE homogenizer AM-6 was a product of Nihonseiki Kaisa Ltd. HiPrep ${ }^{\mathrm{TM}}$ 16/10 DEAE FF anion exchange column and Superdex ${ }^{\mathrm{TM}} 200$ 10/300 GL gel filtration column were purchased from Amersham Biosciences Co. $\mathrm{ACL}^{\circledR}$ Coagulation analyzer $\left(\mathrm{ACL}^{\circledR} 7000\right)$ and blood coagulation assay kits (HemosIL ${ }^{\mathrm{TM}}$ APTT Lyophilized silica for APTT, HemosIL $^{\mathrm{TM}}$ TT, and HemosIL ${ }^{\mathrm{TM}}$ Factors Deficient Plasma were produced from Instrumentation Laboratory Co. Human blood coagulant factors (Tissue factor, FII, FIIa, FVa, FXa) were obtained from Haematologic Technologies, Inc. Fibrinogen and plasmin were purchased from Sigma Chemical Co. BIAcore ${ }^{\circledR} 2000$ system for surface Plasmon resonance (SPR) analysis, sensor chip CM5, surfactant P20, HBS buffer (10 mM HEPES, $0.15 \mathrm{M} \mathrm{NaCl}, 3.4 \mathrm{mM}$ EDTA, $0.05 \%$ surfactant $\mathrm{P} 20, \mathrm{pH}$ 7.4) and amine-coupling kit containing $N$-hydroxysuccinimide (NHS), $N$-ethyl- $N$-(3-diethylaminopropyl) carbodiimide (EDS) and ethanolamine hydrochloride were obtained from Biacore $\mathrm{AB}$ Co.

All other chemicals used in this study were of analytical grade and the highest purity.

Purification of an exogenous anticoagulant protein from $T$. granosa. All present operations were carried out at $4^{\circ} \mathrm{C}$ unless stated otherwise. After removing salts and other contaminants, edible parts $(100 \mathrm{~g})$ of $T$. granosa were homogenized with $50 \mathrm{mM}$ Tris-HCl buffer ( $\mathrm{pH}$ 7.4) and stirred with same buffer for $24 \mathrm{~h}$. The homogenates were centrifuged at $9,500 \times \mathrm{g}$ for $15 \mathrm{~min}$ and treated by $150 \mathrm{ml}$ of $20 \% \mathrm{CCl}_{4}$ to remove lipid. Soluble extracts in water layer were desalted by an electrodialyzer (Micro Acilyzer Model G3, Asahi Chemical Industry Co.) with a 1,000 Da molecular weight cut-off (MWCO) membrane (Asahi Chemical Industry Co.) until conductivity is under $0.1 \mathrm{~mA}$ of electric current. The dialysate was separated using a HiPrep ${ }^{\mathrm{TM}}$ 16/10 DEAE FF anion exchange column $(16 \times 100 \mathrm{~mm})$ preliminarily equilibrated with $50 \mathrm{mM}$ Tris$\mathrm{HCl}$ buffer ( $\mathrm{pH}$ 7.4) in a fast performance liquid chromatographic system, FPLC ÄKTA (Amersham Bioscience). A linear gradient of $\mathrm{NaCl}(0-2 \mathrm{M})$ in the same buffer was maintained at a flow rate of $1.5 \mathrm{ml} / \mathrm{min}$ and $5.0 \mathrm{ml}$ per a fraction was collected. Absorbance was monitored at $280 \mathrm{~nm}$ (Fig 1A) and anticoagulant activity was evaluated by blood coagulation assay for thrombin time (TT) as described herein. The pooled fraction (e) exhibiting the highest activity was subsequently loaded onto a Superdex ${ }^{\mathrm{TM}} 200$ 10/300
GL gel filtration column $(10 \times 300 \mathrm{~mm})$ with distilled water at a flow rate of $0.5 \mathrm{ml} / \mathrm{min}$ (Fig. 1B). The active fraction (e-2) separated through consecutive FPLC columns was migrated on $15 \%$ denatured SDS-PAGE (Laemmli, 1970) and stained with Coomassie Brilliant Blue R-250 (Panel in Fig. 1B). The fraction e-2 was re-separated with Superdex ${ }^{\mathrm{TM}} 200$ 10/300 GL gel filtration column $(10 \times 300 \mathrm{~mm})$ at a flow rate of $0.2 \mathrm{ml} / \mathrm{min}$. The homogeneous T. granosa anticoagulant protein (TGAP) was analyzed using ESIQTOF MS/MS after trypsin digestion.

During chromatographic process, protein concentration was determined according to the method of Bradford et al. (1976) using bovine serum albumin as a standard material, and specific activity on each step was summarized in Table 1.

Protein sequencing and identification by mass analysis and database search. All MS/MS experiments were performed on a QTOF tandem mass spectrometer (Micromass Co.) equipped with a nano-ESI source. The trypsinolytic peptides extracted from SDSgel were desalted using C18 Zip-Tips (Millipore Co.). An approximately $5 \mu \mathrm{l}$ of the sample was placed into a metal-coated glass capillary (Protana Co.). The applied voltage to the capillary to produce an electospray was $1,500 \mathrm{eV}$, and cone voltage was $30 \mathrm{eV}$. MS/MS spectra were acquired in data dependant MS/MS mode, of which collision energy was step increased to 25,30 , and $35 \mathrm{eV}$ from $10 \mathrm{eV}$. Argon was introduced as a collision gas at a pressure of $10 \mathrm{psi}$. The instrument was calibrated externally, and no postacquisition rTAPlibration of MS/MS spectra was performed. For protein identification, MS/MS spectra were searched by MASCOT (Matrix science, http://www.matrixscience.com, UK) using NCBInr database. Mass tolerance was set at $\pm 1.0 \mathrm{Da}$ for the masses of peptide precursors and at $\pm 0.8 \mathrm{Da}$ for the masses of fragment ions. Proteins containing at least one significant peptide (individual score) were selected from database search results.

Blood coagulation and fibrinolytic assay. Nine parts of blood was drawn by venipuncture into one part of $3.2 \%$ sodium citrate from healthy volunteers and pooled. The blood was separately centrifuged at $1,600 \times \mathrm{g}$ for $10 \mathrm{~min}$ to obtain platelet poor plasma (PPP). All coagulation assays were performed with three individual replicates using the $\mathrm{ACL}^{\circledR} 7000$ coagulation analyzer and diagnostic kit, and mean values were taken. Briefly, normal citrated PPP $(80 \mu \mathrm{l})$ was incubated with sample solution $(20 \mu \mathrm{l})$ for $3 \mathrm{~min}$ at $37^{\circ} \mathrm{C}$. For activated partial thromboplastin time (APTT) assay, $100 \mu \mathrm{l}$ of APTT reagent added to the mixture (PPP and sample) was incubated at $37^{\circ} \mathrm{C}$ for $3 \mathrm{~min}$, and clotting time was immediately recorded after the addition of $100 \mu \mathrm{l}$ of $20 \mathrm{mM} \mathrm{CaCl}_{2}$. In prothrombin time (PT) assay, PT reagent was added to the incubated mixture of PPP (80 il) and sample $(20 \mu \mathrm{l})$, and clotting time (s) was recorded. For thrombin time (TT) measurement, $100 \mu \mathrm{l}$ of anticoagulant was incubated with human thrombin (100 $\mu \mathrm{l})$ for $3 \mathrm{~min}$ at $37^{\circ} \mathrm{C}$, and clotting time was determined after the addition of $200 \mu \mathrm{l}$ PPP. For specific factor inhibitory assays, HemosIL ${ }^{\mathrm{TM}}$ Factors Deficient Plasma kits (Instrumentation Laboratory Co.) were used according to the manufacturing manual, and effects of $\mathrm{pH}$, temperature, and cation on TGAP activity were tested on the basis of TT assay according to our previous method (Jung et al., 2002). 

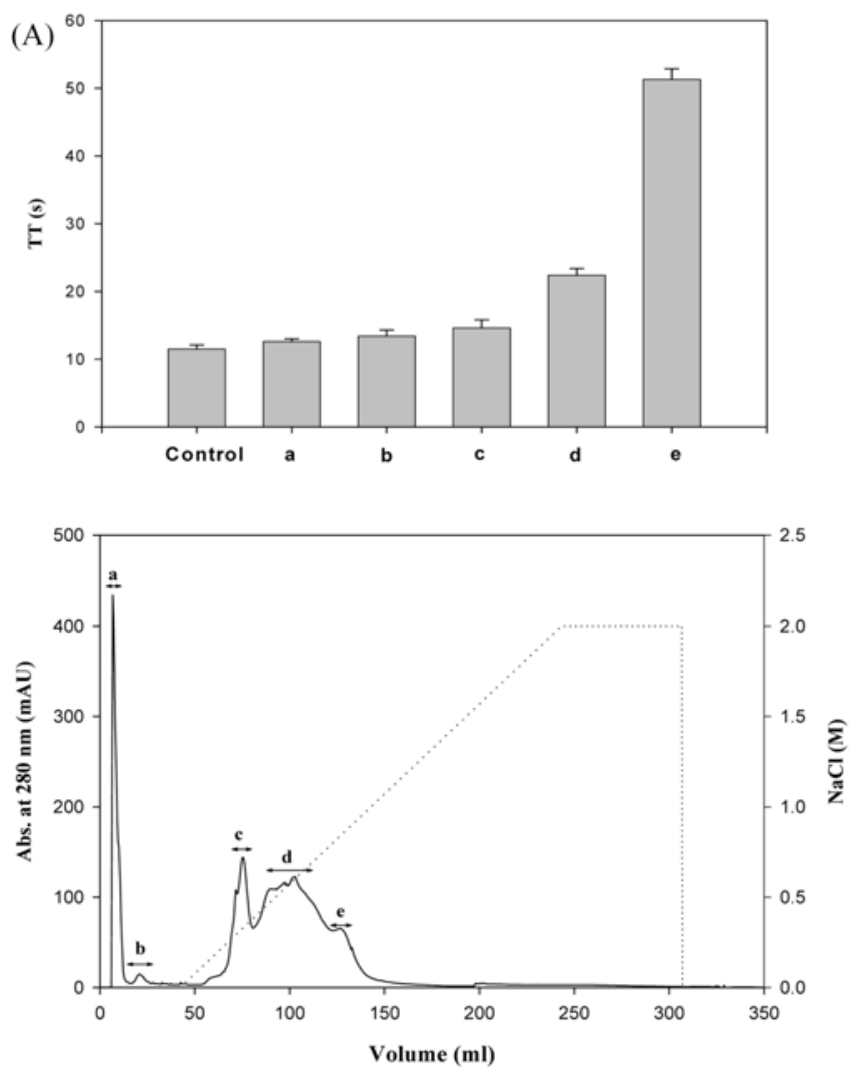
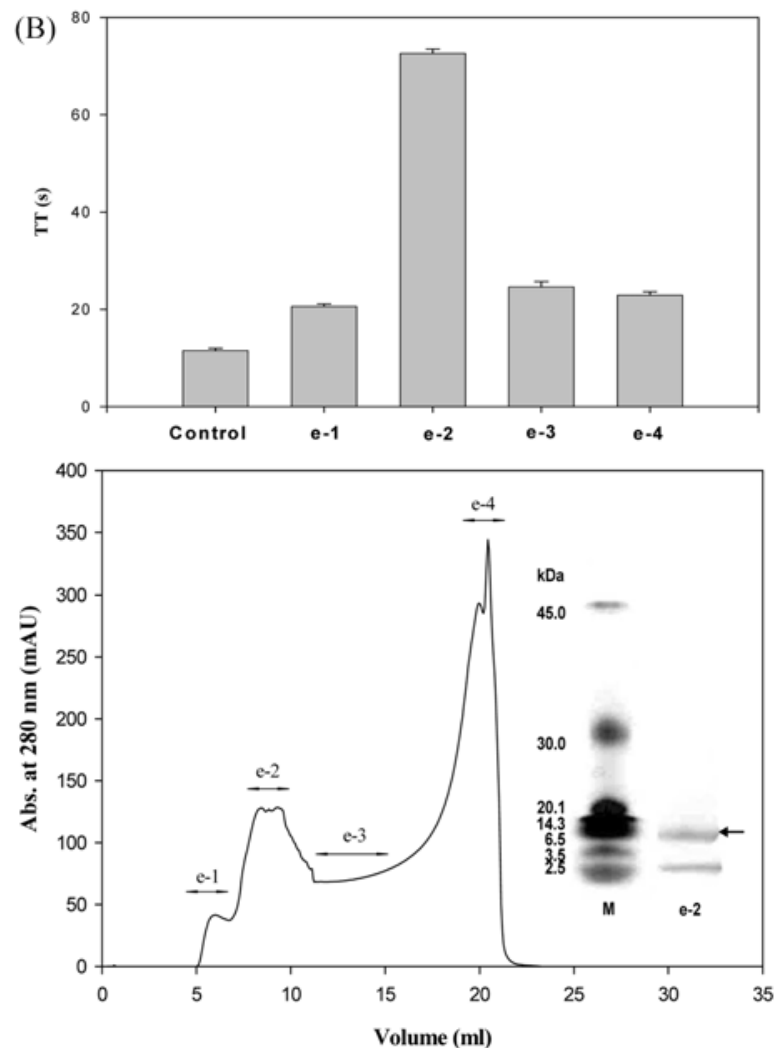

Fig. 1. Purification profiles and anticoagulant activity of $T$. granosa anticoagulant (TGAP). (a) Anion exchange chromatography on a HiPrep $^{\mathrm{TM}} 16 / 10$ DEAE FF anion exchange column $(16 \times 100 \mathrm{~mm})$ preliminarily equilibrated with $50 \mathrm{mM}$ Tris- $\mathrm{HCl}$ buffer $(\mathrm{pH} 7.4)$ in a fast performance liquid chromatographic (FPLC) system. A linear gradient of $\mathrm{NaCl}(0-2 \mathrm{M})$ in the same buffer was maintained at a flow rate of $1.5 \mathrm{ml} / \mathrm{min}$ and $5.0 \mathrm{ml}$ fractions were collected. The upper panel shows anticoagulant activity on thrombin time (TT, s) (b) Gel filtration chromatography on a Superdex ${ }^{\mathrm{TM}} 20010 / 300$ GL gel filtration column $(10 \times 300 \mathrm{~mm})$ preliminarily equilibrated with distilled water. A fraction was collected to $3.0 \mathrm{ml}$ at a flow rate of $0.5 \mathrm{ml} / \mathrm{min}$. The upper panel shows anticoagulant activity on thrombin time (TT, s). Inner-panel in Fig. 1(b) is a SDS-PAGE profile of active fraction (e-2) under denaturing conditions. Sample $(5 \mu \mathrm{g})$ incubated with $2 \%$ 2-mercaptoethanol for $5 \mathrm{~min}$ at $100^{\circ} \mathrm{C}$ was loaded on $15.0 \%$ slab gel and stained with Coomassie Brilliant Blue R-250. Molecular markers (lane $\mathrm{M})$ are ovalbumin $(45 \mathrm{kDa})$, carbonic anhydrase (30 kDa), lysozyme (14.3 kDa), aprotinin $(6.5 \mathrm{kDa})$, insulin $\beta$ chain $(3.5 \mathrm{kDa})$, and insulin $\alpha$ chain $(2.5 \mathrm{kDa})$. The arrow indicated the final active fraction (TGAP) re-separated with Superdex ${ }^{\mathrm{TM}} 20010 / 300 \mathrm{GL}$ gel filtration column $(10 \times 300 \mathrm{~mm})$ at a flow rate of $0.2 \mathrm{ml} / \mathrm{min}$.

Table 1. Purification steps of anticoagulant protein from $T$. granosa

\begin{tabular}{|c|c|c|c|c|c|}
\hline Step & $\begin{array}{l}\text { Total protein } \\
(\mathrm{mg})^{\mathrm{a}}\end{array}$ & $\begin{array}{c}\text { Total } \\
\text { anticoagulation } \\
(\mathrm{s})^{\mathrm{b}}\end{array}$ & $\begin{array}{c}\text { Specific } \\
\text { anticoagulation } \\
\text { activity }(\mathrm{s} / \mathrm{mg})\end{array}$ & $\begin{array}{l}\text { Purification } \\
\quad \text { fold }\end{array}$ & $\begin{array}{l}\text { Yield } \\
(\%)\end{array}$ \\
\hline Crude extracts & 876.6 & 65657.3 & 74.9 & 1 & 100 \\
\hline $\begin{array}{l}\text { Anion exchange chromatography on HiPrep }{ }^{\mathrm{TM}} \\
16 / 10 \text { DEAE FF anion exchange column }\end{array}$ & 9.5 & 2641.9 & 278.1 & 3.7 & 40.2 \\
\hline $\begin{array}{l}1^{\text {st }} \text { Gel chromatography on Superdex } \\
10 / 300 \text { GL gel filtration column }\end{array}$ & 1.6 & 641.9 & 401.2 & 5.4 & 9.8 \\
\hline $\begin{array}{l}2^{\text {st }} \text { Gel chromatography on Superdex } \\
10 / 300 \text { GL gel filtration column }\end{array}$ & 0.9 & 537.8 & 597.6 & 8.0 & 8.2 \\
\hline
\end{tabular}

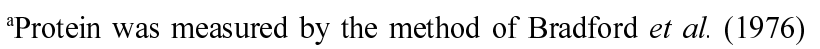

${ }^{b}$ The clotting time was measured using the mixture of citrated normal human blood plasma (80 $\mu$ l) and T. granosa anticoagulant (20 il) by thrombin time assay.

Fibrinolytic activity was estimated by the previous fibrin plate assay (Rajapakse et al., 2005) using plasmin as the standard. The fibrinogen solution $(4.0 \mathrm{ml}$ of $0.5 \%$ human fibrinogen in $0.1 \mathrm{M}$ barbital buffer, $\mathrm{pH} 7.7$, containing $1.6 \mathrm{mM} \mathrm{CaCl}_{2}, 0.7 \mathrm{mM} \mathrm{MgCl}$ 
and $92.0 \mathrm{mM} \mathrm{NaCl})$ was mixed with agarose solution $(4.0 \mathrm{ml}$ of $2.0 \%$ agarose in the same barbital buffer), $0.2 \mathrm{ml}$ of $20 \mathrm{NIH} \mathrm{U} / \mathrm{ml}$ thrombin in $0.9 \%$ saline and $0.1 \mathrm{ml}$ of $1.0 \mathrm{M} \mathrm{CaCl}_{2}$. The mixture was poured into a Petri-dish and allowed to stand for $1 \mathrm{~h}$ at room temperature to obtain a fibrin clot layer. Various concentrations of sample solutions $(0-600 \mu \mathrm{M})$ in plasminogen $(10 \mu \mathrm{l})$ were spotted on the fibrin layer and incubated at $37^{\circ} \mathrm{C}$ for $10 \mathrm{~h}$. Fibrinolytic activity was determined by measuring two perpendicular diameters of the lysed zone.

Surface plasmon resonance (SPR) spectroscopy. In order to identify binding affinity of TGAP to blood coagulation factor, surface plasmon resonance (SPR) sensorgrams were determined by a BIAcore $2000^{\circledR}$ system (Pharmacia Biosensor). A ligand protein were directly immobilized on a CM5 sensor chip by coupling through free amino group to a carboxylated dextran matrix, activated with a mixture of N-hydroxysuccinimide (NHS) and N-ethyl-N'-(3diethylaminopropyl) carbodiimide (EDS) after pH scouting. Sensor chip surface was coated with a ligand protein in $10 \mathrm{mM}$ sodium acetate buffer at optimal $\mathrm{pH}$, and unreacted groups were blocked with $1 \mathrm{M}$ ethanolamine, $\mathrm{pH}$ 8.5. Among four flow cells in the sensor chip, each first flow cell, similarly activated and blocked without immobilization of protein, served as a control surface. After immobilization of coagulation factors on the sensor chip, an analyte $(50 \mu \mathrm{g} / \mathrm{ml})$ was injected onto the surface of sensor chip in HBS buffer (Hepes-buffered saline containing $1 \mathrm{mM}$ CHAPS, $0.005 \%$ surfactant $\mathrm{P} 20,5 \mathrm{mM} \mathrm{CaCl}_{2}, 10 \mathrm{nM}$ tissue factor, $\mathrm{pH} \mathrm{7.4)} \mathrm{at} 25^{\circ} \mathrm{C}$ at a flow rate of $30 \mu \mathrm{l} / \mathrm{min}$ for $3 \mathrm{~min}$ followed by $2 \mathrm{~min}$ of dissociation. Resonance was monitored as a function of time and binding affinity represented as a resonance or response unit (RU) in real time.

Cytotoxicity assay. Venous endothelial cell line (ECV-304) were maintained in RPMI 1640 medium containing 10\% (v/v) heat inactivated fetal bovine serum (FBS) supplemented with penicillin $(100 \mathrm{U} / \mathrm{ml})$ and streptomycin $(100 \mu \mathrm{g} / \mathrm{ml})$ at $37^{\circ} \mathrm{C}$ under $5 \% \mathrm{CO}_{2}$ in the air. Cytotoxic effect of exogenous TGAP on endothelial cell (ECV-304) was measured by using MTT assay. The cells were seeded in a 96-well plate at concentration of $2 \times 10^{4}$ cells $/ \mathrm{ml}$ using RPMI medium. After $16 \mathrm{~h}$ (at $37^{\circ} \mathrm{C}$, in a humidified atmosphere of $5 \% \mathrm{CO}_{2}$ ), TGAP was treated to the wells at a concentration range from 5 to $500 \mu \mathrm{g} / \mathrm{ml}$. The cells were then further incubated for an additional $72 \mathrm{~h}$ at $37^{\circ} \mathrm{C}$. MTT stock solution $(50 \mu \mathrm{lof} 2 \mathrm{mg} / \mathrm{ml}$ in PBS) was then added to each well for a total reaction volume of $250 \mu \mathrm{l}$. After incubating for $4 \mathrm{~h}$ in a humidified atmosphere of $5 \%$ $\mathrm{CO}_{2}$ at $37^{\circ} \mathrm{C}$, the plate was centrifuged at $800 \mathrm{~g}$ for $5 \mathrm{~min}$ and the supernatants were aspirated to remove untransformed MTT. The formazan crystals in each well were dissolved in $150 \mu$ l of DMSO. The amount of purple formazan was determined by measuring the absorbance at $540 \mathrm{~nm}$ using an enzyme-linked immunosorbent assay (ELISA) plate reader (Ultramark Microplate Imaging System 110/230 V, Bio-Lab Co.). For treated cells, viability was expressed as a percentage of control cells. All determinations were carried out in triplicate.

Statistics. Results are presented as mean \pm SD of the mean $(n=3)$. Student's $t$-test was used to determine the level of significance unless otherwise stated.

\section{Results and Discussion}

In the preliminary test for anticoagulant activity from marine organisms, blood coagulation inhibitory activity was detected from granulated ark ( $T$. granosa) extracts. The soluble extracts prolonged blood clotting time on TT but not APTT or PT. A control clotting time on TT $(11.6 \pm 0.4 \mathrm{~s})$ was prolonged to $39.0 \pm 0.7$ by the addition of $20 \mu \mathrm{l}$ extracts $(5.7 \mathrm{mg} / \mathrm{ml})$. This result implies that the extracts inhibit formation of thrombin (FIla) by negative interactions with the relative factors (FII, FVa, FXa, phospholipids, etc.) in the blood coagulation pathway. In the fibrinolytic assay, $T$. granosa extracts (0-10 $\mathrm{mg} / \mathrm{ml})$ could not show significant activity $(P<0.05)$.

To investigate biochemical and anticoagulant properties, the extract was purified by the consecutive FPLC system with a HiPrep $^{\mathrm{TM}}$ 16/10 DEAE FF anion exchange column and Superdex $^{\mathrm{TM}} 200$ 10/300 GL gel filtration column (Fig. 1). As summarized in Table 1, an overall purification fold of 8.0 was produced through all chromatographic process. The purified T. granosa anticoagulant protein (TGAP) potently prolonged the normal clotting time on TT to $112.8 \pm 1.2 \mathrm{~s}$ in dosedependant manner (Fig. 2). As reported in our previous study (Jung et al., 2002), we also purified anticoagulant protein from other marine bivalve (S. broughtonii), but it could prolong different coagulation time, the activated partial thromboplastin time (APTT) corresponding to inhibition of the intrinsic blood coagulation pathway. In the study, the addition of $20 \mathrm{ml}$ of $S$. broughtonii anticoagulant $(0-100 \mathrm{mg} /$ $\mathrm{ml}$ ) prolonged a $32 \mathrm{~s}$ control clotting time from $49 \mathrm{~s}$ to $325 \mathrm{~s}$.

In the results of ESI-QTOF tandem mass analysis and database search, it was revealed that TGAP has molecular mass of 7,698 Da, in similar with the results in SDS-PAGE (panel in Fig. 1B). The results also showed that a partial

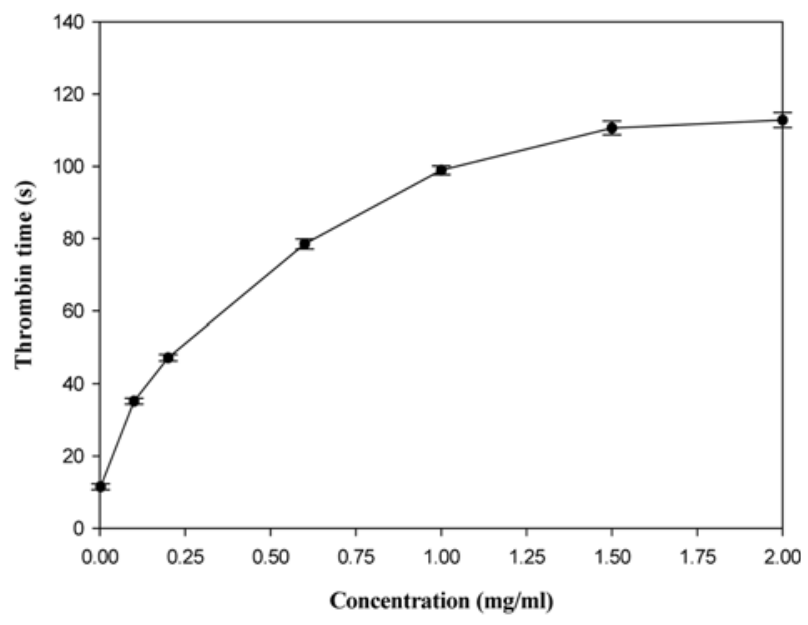

Fig. 2. Dose-dependant prolongation of T. granosa anticoagulant (TGAP) on thrombin time (TT). TT assay was performed with three individual replicates using the $\mathrm{ACL}^{\circledR} 7000$ Coagulation analyzer and diagnostic kit, and mean values were taken as described herein. Samples incubated for $3 \mathrm{~min}$ at $37^{\circ} \mathrm{C}$ contain the normal citrated PPP $(80 \mu \mathrm{l})$ and TGAP $(20 \mu \mathrm{l})$. 


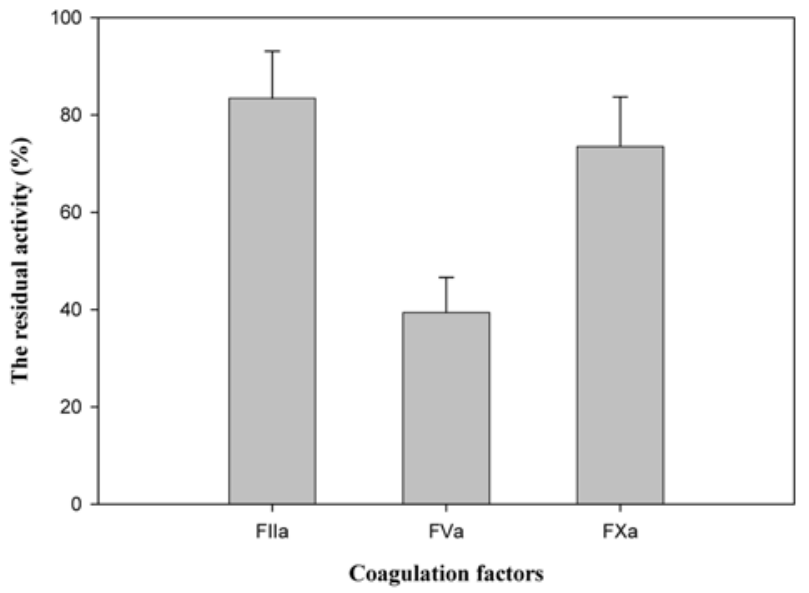

Fig. 3. Specific-factor inhibitory patterns of $T$. granosa anticoagulant (TGAP). TGAP specifically inhibits FVa among the major activated factors (FIIa, FVa, FXa) in the thrombinformation pathway. For specific factor inhibitory assays, HemosIL ${ }^{\mathrm{TM}}$ Factors Deficient Plasma kits (Instrumentation Laboratory Co., Lexington, MA) were used according to the manufacturing manual.

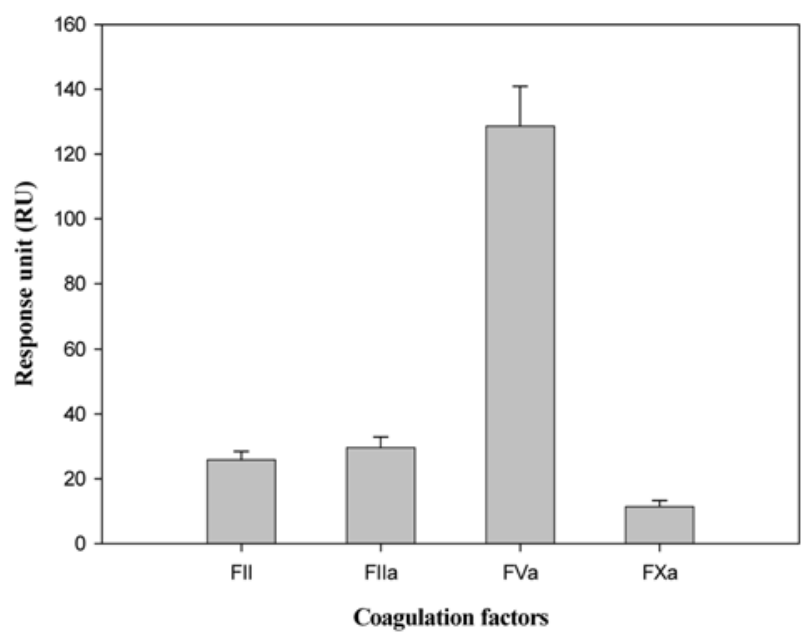

Fig. 4. Binding affinity assay of $T$. granosa anticoagulant (TGAP) to blood coagulation factors using surface plasmon resonance (SPR) spectrometer. The resonance units (RUs) were measured for identifying molecular interaction between TGAP (ligand) and FII, FIIa, FVa, FXa (analytes). In addition, the addition of TAF could inhibit molecular interaction between FII and FVa in dose-dependent manner (Fig. 5) and the $\mathrm{IC}_{50}$ value of TGAP was calculated as approximately $77.9 \mathrm{nM}$. However, FXa could bind to FVa in the present of TGAP (data not shown).

sequence derived from trypsinolytic fragments of TGAP, HTHLQRAPHPNALGYHGK, has a high identity (64\%) with serine/threonine kinase derived from Rhodopirellula baltica (order Planctomycetales, marine bacteria) (Gloeckner et al., 2003).

Specific factor inhibitory assay showed that TGAP could specifically inhibit FVa among the major activated factors

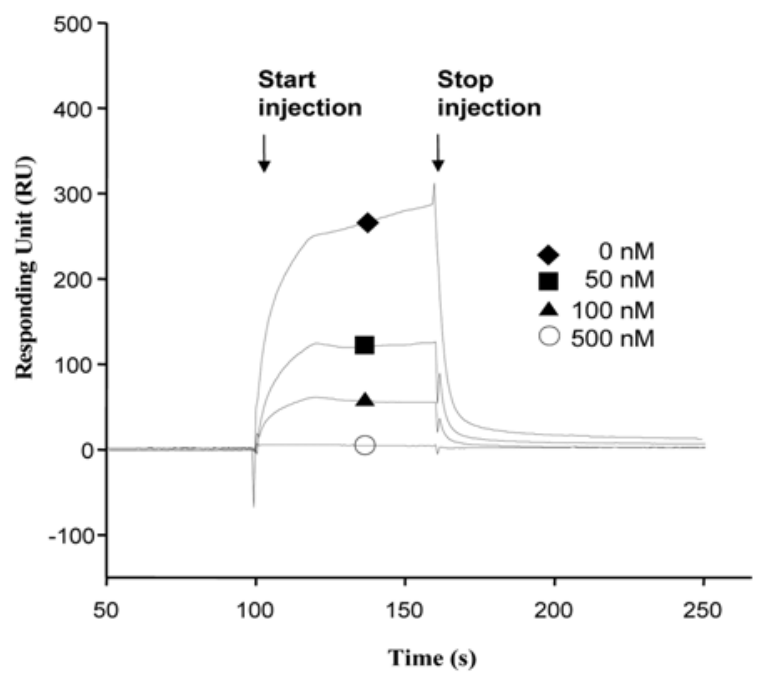

Fig. 5. Surface plasmon resonance (SPR) real-time sensorgrams on interaction between FVa and FII in the present of T. granosa anticoagulant $(0-500 \mathrm{~nm}$ of TGAP).

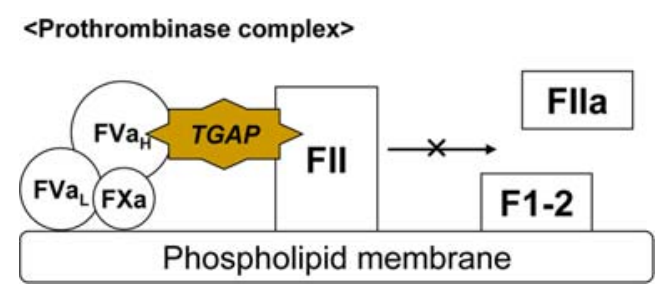

Fig. 6. The anticoagulant mechanism of TGAP to FVa in the prothrombin complex. This diagram illustrates that the regular conversion of prothrombin (FII) to thrombin (FIIa) might be inhibited by negative interaction (blocking) of TGAP on the binding site of FII $\left(\mathrm{FVa}_{\mathrm{H}}\right)$.

(FIIa, FVa, FXa) in the thrombin-formation pathway (Fig. 3). The activated factor $\mathrm{V}(\mathrm{FVa})$ is considered as an essential component in prothrombinase complex, converting prothrombin (FII) into thrombin (FIIa). The prothrombinase complex comprises FXa and FVa, which in the presence of calcium ions assemble on negatively charged phospholipids membranes. In the facts, it is supposed that the present of TGAP might interrupt regular formation of prothrombinase complex by negative interaction to FVa. As reported by Koyama et al. (1998), plancinin, a potent anticoagulant peptide isolated from starfish (Acanthaster planci) has comparatively similar molecular weight $(7.5 \mathrm{kDa})$ with TGAP, and it also inhibit prothombinase complex by anticoagulant action of placinin in activation step of FII and FXa.

In the direct-binding assay using SPR sensorgraphy (Fig. 4), resonance units (RUs) were measured for identifying molecular interaction between TGAP (ligand) and FII, FIIa, FVa, FXa (analytes). The results illustrated that the TGAP could potently interact to FVa, but not FIIa or FXa. In addition, the addition of TGAP could inhibit molecular interaction between FII and FVa in dose-dependent manner 

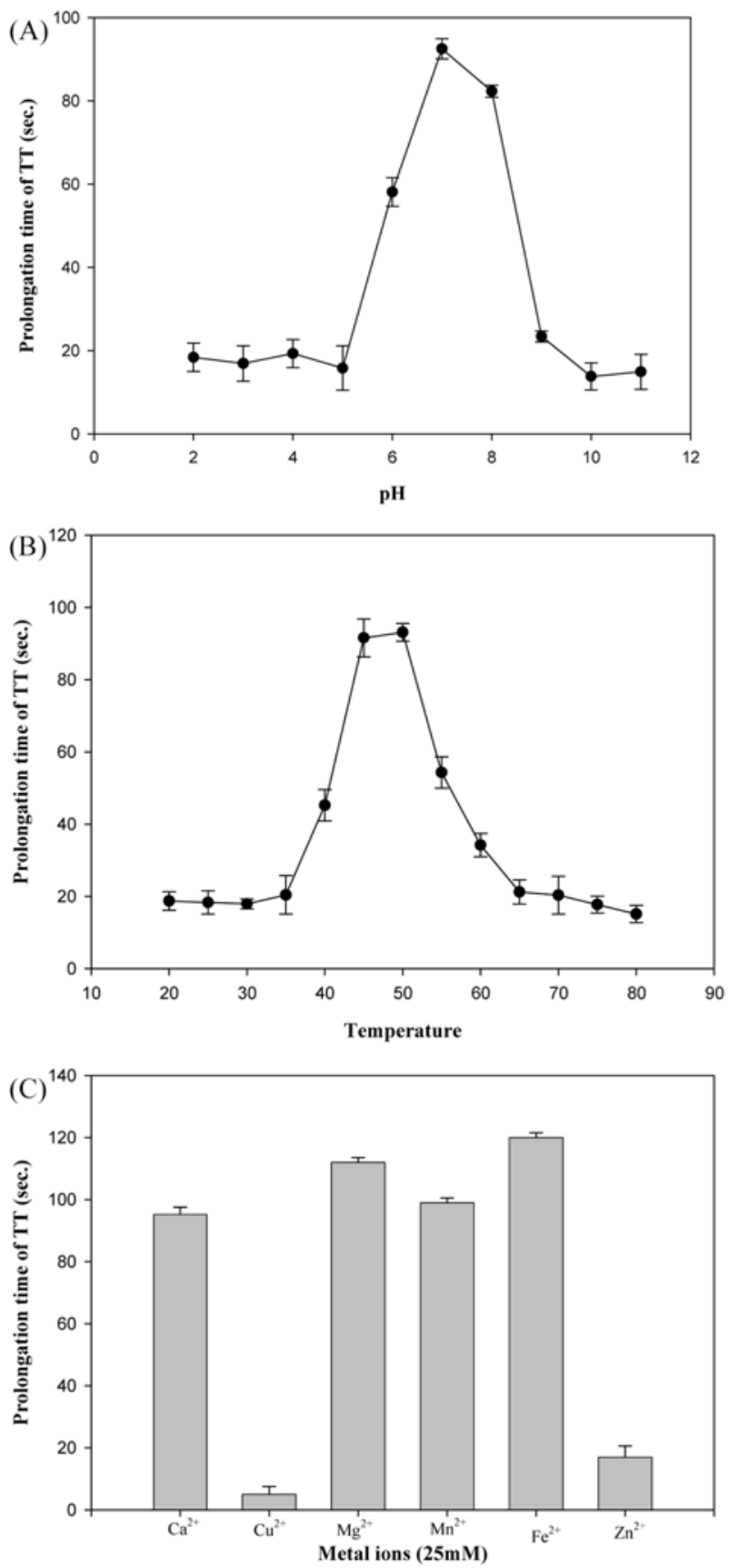

Fig. 7. Effects of various (a) $\mathrm{pH}$ (b) temperature (C) and (c) divalent metal ion on anticoagulant activity of $T$. granosa anticoagulant protein (TGAP). Effects of $\mathrm{pH}$, temperature, and cation on TGAP activity were measured on the basis of TT assay. The results were expressed as the means of three measurements.

(Fig. 5) and the $\mathrm{IC}_{50}$ value of TGAP was calculated as approximately $77.9 \mathrm{nM}$. However, FXa could bind to FVa in the present of TGAP (data not shown). FVa is comprised of an $\mathrm{NH}_{2}$-terminal derived heavy chain $(\mathrm{Mr}=94 \mathrm{kDa})$ and a $\mathrm{COOH}$-terminal derived light chain $(\mathrm{Mr}=74 \mathrm{kDa})$ which remain associated in the presence of calcium ions. In the

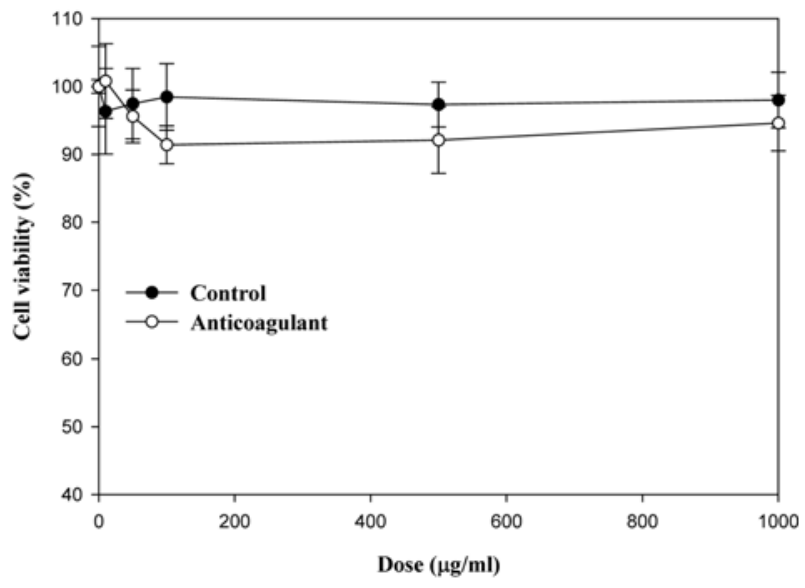

Fig. 8. Cytotoxicity of T. granosas anticoagulant (TGAP) on the viability of venous endothelial cell line (ECV304) in dosedependent manner. A control is defined as untreated group. Three repeats were performed for each group.

formation of prothrombinase complex, molecular interaction between FVa and FXa is mediated by both heavy chain $\left(\mathrm{FVa}_{\mathrm{H}}\right)$ and light chain $\left(\mathrm{FVa}_{\mathrm{L}}\right)$ of $\mathrm{FVa}$, while the binding of $\mathrm{FII}$ to FVa is mediated solely by the heavy chain (Mann et al., 1988).

As demonstrated in Fig. 6, these results suggests that the prolongation of blood clotting time in the present of TGAP be caused by interrupting molecular interaction between FII and $\mathrm{FVa}_{\mathrm{H}}$ domain in the formation of prothrombinase complex to convert FII to thrombin (FIIa).

In the fibrinolytic assay, TGAP (0-1 mM) could not show significant activity $(P<0.05)$. Effects of $\mathrm{pH}$, temperature, and cation on TGAP activity were measured on the basis of TT assay. TGAP was stable in the range of $\mathrm{pH} 7.0$ and 8.0, but the activity at below $\mathrm{pH} 6.0$ and above $\mathrm{pH} 9.0$ was destroyed (Fig. 7A). TGAP activity could maintain at temperatures from $40^{\circ} \mathrm{C}$ to $60^{\circ} \mathrm{C}$, but the activity was decreased at other temperatures (Fig. 7B). After removing cations by EDTAtreatment and dialysis, TGAP activity could be recovered by addition of $\mathrm{Mg}^{2+}$ and $\mathrm{Mn}^{2+}$ besides $\mathrm{Ca}^{2+}$ (Fig. 7C). This result suggests that TGAP may be easily interacted with FVa by stabilization and coordination of divalent cations; moreover, $\mathrm{Mg}^{2+}$ and $\mathrm{Mn}^{2+}$ might play a role as a substitute of $\mathrm{Ca}^{2+}$ for the anticoagulant activity of TGAP on the blood coagulation cascade.

Some synthetic anticoagulant was reported to cause severe side-effects such as development of thrombocytopenia (Gurbuz et al., 2005), hemorrhagic effect (Kakkar et al., 1986), antithrombin deficiencies, incapacity to inhibit thrombin bound to fibrin, and so on. To investigate cytotoxicity of TGAP, we performed MTT assay on venous endothelial cell line (ECV 304). As shown in Fig. 8, the result of MTT assay illustrated TGAP has no significant cytotoxicity $(P<0.05)$ to the venous endothelial cells.

In conclusion, a novel inhibitory protein against blood 
coagulation factor Va (FVa) was purified from muscle protein of granulated ark (Tegillarca granosa, order Arcoida, marine bivalvia). The exogenous anticoagulant protein (TGAP) could be interacted with FVa, thus blood coagulation time can be prolonged by inhibition of the activation of prothrombin. Although more studies on biochemical property and medicinal application are still needed, this study will be allowed to give some information on pharmaceutical resources or biophysiological benefits as a non-cytotoxic anticoagulant protein derived from marine organism.

Acknowledgments This research was supported by a grant (p-2004-01) from the Marine Bioprocess Research Center of the Marine Bio 21 Center funded by the Ministry of Maritime Affairs and Fisheries, Republic of Korea. This work was also supported by the Korea Research Foundation Grant (KRF2004-908-F00005).

\section{References}

Bradford, M. (1976) A rapid and sensitive method for the quantitation of microgram quantities of protein utilizing the principle of protein-dye binding. Anal. Biochem. 72, 248-254.

Davie, E. W., Fujikawa, K. and Kisel, W. (1991) The coagulation cascade: Initiation, Maintenance, and Regulation. Biochemistry 30, 10363-10370.

Gloeckner, F. O., Kube, M., Bauer, M., Teeling, H., Lombardot, T., Ludwig, W., Gade, D., Beck, A., Borzym,K., Heitmann, K., Rabus, R., Schlesner, H., Amann, R. and Reinhardt, R. (2003) Complete genome sequence of the marine planctomycete
Pirellula sp. strain 1. Proc. Natl. Acad. Sci. USA 100, 82988303.

Gurbuz, A. T., Elliott, W. G. and Zia, A. A. (2005) Heparininduced thrombocytopenia in the cardiovascular patient: diagnostic and treatment guidelines. Eur. J. Cardiothorac. Surg. 27, 138-149.

Jung, W. K., Je, J. Y., Kim, H. J. and Kim, S. K. (2002) A novel anticoagulant protein from Scapharca Broughtonii. J. Biochem. Mol. Biol. 35, 199-205.

Kakkar, V. V., Kakkar, S., Sanderson, R. M. and Peers, C. E. (1986) Efficacy and safety of two regimes of low molecular weight heparin fragment (fragmin) in preventing post-operative venous thromboembolism. Haemostasis 16, 19-24.

Kalafatis, M., Rand, M. D. and Mann, K. G. (1994) Factor Vamembrane interaction is mediated by two regions located on the light chain of the cofactor. Biochemistry 33, 486-493.

Koyama, T., Noguchi, K., Aniya, Y. and Sakanashi, M. (1998) Analysis for sites of anticoagulant action of plancinin, a new anticoagulant peptide isolated from the starfish Acanthaster planci, in the blood coagulation cascade. Gen. Pharmacol. 31, 277-282.

Laemmli, U. K. (1970) Cleavage of structural proteins during the assembly of the head of bacteriophage T4. Nature 227, 680685.

Mann, K. G., Jenny, R. J. and Krishnaswamy, S. (1988) Cofactor proteins in the assembly and expression of blood clotting enzyme complexes. Annu. Rev. Biochem. 57, 915-956.

Mayer, A. M. S. and Hamann, M. T. (2004) Marine pharmacology in 2000. Mar. Biotechnol. 6, 37-52.

Rajapakse, N., Jung, W. K., Mendis, E., Moon, S. H. and Kim, S. K. (2005) A novel anticoagulant derived from fish protein hydrolysate inhibits factor XIIa and platelet aggregation. Life Sci. 76, 2607-2619. 